\title{
El léxico mexicano de la viruela en los albores de la Independencia: los datos de la Instrucción formada para administrar la vacuna (México, 1814)
}

\section{Mexican Lexicon of Smallpox during the Beginnings of the Independence: Data from the Instrucción formada para administrar la vacuna (Mexico, 1814)}

Carlos Paredes García [carparegarc@gmail.com]

Universidad Autónoma de Querétaro, México

\section{RESUMEN}

El estudio del léxico de la medicina en América ha sido poco explorado por los investigadores, en especial durante el ochocientos. El objetivo de este trabajo es analizar el vocabulario usado para referirse a la viruela y se compara con los hallazgos encontrados en otros trabajos para el siglo pasado, así como se estudia la introducción de los nuevos descubrimientos científicos a los textos médicos. Los resultados muestran una continuación de las tendencias reconocidas para el siglo pasado, sin embargo, también se identifican diferentes clasificaciones usadas para la enfermedad y asimismo, la diferencia más marcada es la introducción del término de la vacuna como método de tratamiento para la viruela.

\section{Palabras clave}

Historia del español; léxico de la medicina; viruela; México; siglo XIX

\begin{abstract}
The study of medicine lexicon in America has not been explored by the researchers, especially during the 18th century. The objective of this paper is to analyze the lexicon of smallpox and it is compared to what it is observed in other works to the past century, also it is studied the introduction of the vaccine to medical texts. The results show the continuation of the tendencies observed to the past century, however, it is also identified different classifications used to the disease. At the same time, the most remarkable difference is the introduction of the term vaccine, as the new method to treat smallpox.
\end{abstract}

\section{KEYWORDS}

History of Spanish language; medical lexicon; smallpox; Mexico; 19th century

RECIBIDO 2020-04-02; ACEPTADO 2020-08-23 


\section{Introducción: la historia léxica de la medicina americana}

Si bien existen ya una serie de trabajos importantes sobre la historia del léxico de la medicina (Gómez de Enterría 2015, 2016; Gutiérrez Rodilla 1993, 2014) cabe indicar que la mayor parte de ellos ofrecen un panorama que se ve limitado a la península ibérica. Más allá de eso, existen trabajos de interés, aunque todavía muy escasos que abordan la situación presente en otras zonas del mundo hispánico como México (Gómez de Enterría 2014; Ramírez Luengo 2014, 2015) y en los que se explora la situación lingüística encontrada en este país igualmente durante el Siglo de las Luces.

Frente a esta atención concentrada en el siglo XVIII, la centuria siguiente constituye, en el caso de América, una zona aún inexplorada para los investigadores que se interesan por el léxico de la medicina. Este hecho demuestra la necesidad de llevar a cabo nuevos estudios que aporten datos sobre esta temática, y que, con ello, permitan explicar la situación del léxico español de la medicina en unos momentos caracterizados por las transformaciones que tienen lugar tanto en la política americana como en el mismo ámbito médico de ambos lados del Atlántico a raíz de los nuevos descubrimientos que se están produciendo en el área

\section{El documento analizado: la Instrucción de F. M. Calleja (1814)}

Teniendo en cuenta lo que se acaba de indicar, este estudio pretende analizar el léxico relacionado con la viruela, enfermedad de primera importancia en la época, que aparece en un texto divulgativo sobre esta y sobre la vacuna publicado en México durante los primeros años del siglo XIX ${ }^{1}$.

El documento que se ha seleccionado para este análisis tiene como título Instrucción formada para ministrar la vacuna, Como único preservativo del contagio de las viruelas, y en defecto de su fluido inocular con el pus de esta; del modo de conocer y distinguir las calidades naturales, y el método de curarlas ${ }^{2}$. Es publicado en 1814, en pleno conflicto por la independencia, por el virrey de la Nueva España, Félix María Calleja ${ }^{3}$, y aporta una explicación detallada sobre temas muy variados, tales como qué es la vacuna y cómo se conserva, así como las diferencias entre este nuevo método para combatir la viruela y la inoculación, las distintas formas que presenta esta enfermedad o los tratamientos y nombres con los que se le conoce popularmente en la Nueva España de principios del siglo XIX. En cuanto a su función, se puede decir que es un texto de carácter divulgativo, ya que da las herramientas necesarias para que los médicos puedan comunicarse con efectividad con la población en general y les expliquen la enfermedad y su proceso de curación, por lo que resulta

1 La selección de esta enfermedad estriba en que tuvo un impacto en la conquista de América hasta su erradicación (Franco-Paredes, Lammoglia, Santos-Preciado 2004: 322); se trata, además, de uno de los aspectos médicos más importantes del siglo XVIII y los primeros años de la centuria siguiente como señala en Ramírez Luengo (2014: 183).

2 Como se puede ver, se trata de una guía para que los médicos puedan administrar la vacuna que previene la enfermedad; dicho avance tecnológico fue descubierto a finales del siglo anterior en Inglaterra (Stern y Markel 2005: 612), sin embargo, llega a los territorios de la Nueva España durante los primeros años del siglo XIX. En concreto, la obra puede ser encontrada en la Biblioteca Nacional de España, específicamente bajo la signatura VE/1501/1.

3 Nacido en Medina de Campo, España en 1753, llega a la Nueva España en 1789 y actúa como general hasta obtener el cargo de virrey, que desempeña de 1814 a 1816. 
particularmente interesante para los objetivos de este trabajo, y en concreto para el estudio de los campos léxicos que interesa analizar.

A partir de lo anteriormente planteado, los objetivos de este estudio son los siguientes: a) revisar el léxico de esta obra relacionado específicamente con la viruela, así como la terminología médica relacionada con esta enfermedad; b) establecer las coincidencias existentes con el vocabulario sobre ella encontrado por Ramírez Luengo (2014) para la Nueva España del siglo XVIII; y c) buscar posibles novedades decimonónicas que muestren la plasmación léxica del estado de la medicina durante este siglo.

Con el propósito de responder a los objetivos anteriores, a metodología utilizada en este trabajo consta de las siguientes etapas: 1) extracción del léxico relacionado con la viruela presente en el documento; 2) clasificación por campos léxicos de interés, en concreto el vocabulario utilizado para referir a la enfermedad, a algunas de sus fases y a aquellos tratamientos usados para combatirla; 3) análisis de cada elemento desde el punto de vista formal y significativo; y 4) comparación de los resultados con los registrados en obras de la época y con los de la Nueva España dieciochesca (Ramírez Luengo 2014).

\section{El léxico de la viruela en los inicios del siglo XIX: el caso de Nueva España}

Dada su temática, no sorprende que este texto nos presente contenido léxico relacionado con la medicina muy variado y de muy distinto origen, tales como voces latinas del estilo de tiphus o epidermis (DLE 2019: s.v. tifus, epidermis) o nahuatlismos concretos como tianguispepetla o copalche (DAMER 2010: s.v. tianguispepetla, copalchí); sin embargo, el hecho de que el objetivo fundamental del texto sea la lucha contra la viruela, así como la importancia que tiene esta en el Nuevo Mundo (Cortés Riveroll 2008), determina que sea el léxico referente a esta enfermedad el que con más frecuencia se constata.

Como es de esperar, uno de los vocablos que más se reitera dentro de la Instrucción es el nombre de la propia enfermedad, cuya denominación aparece tanto en singular (13 apariciones) como en plural, en este caso de manera mucho más frecuente, con 47 casos $^{4}$. Para ambas posibilidades, los datos muestran dos diferentes significados: el primero referido a la enfermedad (ejemplos 1-2) y el segundo a las características pústulas que esta produce (ejemplos 3-4):

1. Esta se vió en la inoculacion de las viruelas naturales por el año de 1797, en el que fué la epidemia, que á el que estaba ya contagiado del virus varioloso, no se le inoculase y le saliese en la parte, se libertaba del estrago de las viruelas (p. 9)

2. El exponer esta Junta superior de Sanidad todo lo observado en otras, no le parece conveniente en la actualidad, porque seria muy difusa, y podria ofuscar y entorpecer aun el primer tratamiento de la viruela, sin complicacion ni malignidad (p. 14)

4 Se trata, como es sabido, de un término muy tradicional en el ámbito hispánico: Según los datos de CORDE [consulta: 01/09/2019], se registra la primera datación de la palabra viruela en el año 1250 en España, mientras que en México aparece ya en 1532. 
3. Quando empiezan a secarse las viruelas de la cara, aun quando no se presente vicio de estomago, no está por demas purgar al enfermo, ó con dos onzas del maná y media de sal catártica disuelta en quatro onzas de agua caliente (p. 19)

4. Debe tomarse de la viruela ó grano que esté en su estado, esto es, bien blanco y que no empieze á amarillar: en quanto al regimen posterior será el mismo ante dicho para la viruela benigna, con la diferencia que en la inoculada habrá mas libertad (p. 23)

A pesar de que, como se acaba de indicar, ambas posibilidades se utilizan de forma indistinta para los dos valores mencionados -a semejanza de lo que actualmente registra, por ejemplo, el diccionario académico (DLE 2019: s.v. viruela)-, los datos de esta obra parecen demostrar que en el caso de la enfermedad hay una clara preferencia por la segunda de ellas: en efecto, de los 45 casos registrados en la obra del uso de viruela-viruelas para referirse a la enfermedad, el plural aparece en 39 ocasiones, es decir, un $86 \%$, mientras que el singular muestra porcentajes escasos, de apenas el 14\%. Teniendo en cuenta este dato, y en comparación con los presentados por Ramírez Luengo (2014) para el siglo anterior, se advierte un aumento de uso de la forma singular, pues en la Nueva España del siglo XVIII se registra un único caso del singular en contraste con 141 apariciones del plural ( $0.8 \%$ frente al $99.2 \%)$, lo que implica que la tendencia a utilizar el plural para referirse a la dolencia comienza a disminuir ya durante el siglo XIX, en un proceso que lleva hasta la situación actual, con una clara preferencia por el singular en esta función ${ }^{5}$.

Por otro lado, el texto también hace referencia a las distintas fases que se producen en el desarrollo de la enfermedad. En este sentido, y tal como menciona Cortés Riveroll (2008), desde que la persona se contagia del virus de la variola hasta su recuperación final, la viruela se caracteriza por síntomas como fiebre, malestar general, cefalalgia y posteriormente aparición de las pústulas. Todos estos síntomas sirven a los médicos de la época para dividir el ciclo de la enfermedad en diferentes fases que en la Nueva España del siglo XVIII son denominadas tiempos, periodos o estados (Ramírez Luengo 2014: 204), denominaciones que, de acuerdo con los datos del documento, se mantienen de igual forma en la centuria siguiente, con ejemplos como período o estados (ejemplos 5-6):

5. Este primer periodo dura tres o quatro dias, y al fin de estos se manifiestan los granos, que empiezan por la cara, manos, pecho, y extremidades inferiores: manifestada la erupcion, si la viruela es benigna, cesa del todo la calentura (p. 17)

6. A mas de estos síntomas, hay muchos otros que se presentan baxo de diferentes aspectos y complicaciones, tanto en sus principios y estados, quanto en las declinaciones y terminaciones, lo que merece mucha atencion (p. 18)

De igual forma, en la medicina dieciochesca, tanto hispánica como mexicana (Ramírez Luengo, 2014), estos periodos o fases de la enfermedad son divididas en cuatro que se pueden carac-

5 En el México actual, este balance parece haber cambiado drásticamente: Por ejemplo, en CREA [consulta: 01/09/2019], existen tan solo 11 casos de la forma viruelas, en contraste con los 103 casos para el singular. Esto establece una fuerte diferencia con los datos encontrados en la obra y obliga a plantearse en qué momento (y por qué razones) se cambia la preferencia de la forma plural a la singular, cuestión de indudable interés pero que, sin embargo, sale del alcance de este estudio. 
terizar médicamente por el surgimiento de los primeros síntomas, la aparición de las pústulas, la generalización de estas y su desaparición final. Pues bien, si en su corpus del siglo XVIII, Ramírez Luengo (2014: 205) encuentra dos series diferentes para denominar a estas fases -que son principio, aumentó, estado y declinación e invasión, erupción, supuración y desecación-, dentro de la obra analizada en este estudio se encuentra una situación muy semejante a la que se acaba de describir, tanto en lo que se refiere a la existencia de cierta variedad de vocablos para denominarlas como a las propias denominaciones en sí mismas, dado que se encuentran términos como principios para referirse a sus inicios y terminación y declinación para referirse a la última fase de la enfermedad (ejemplo 7):

7. A mas de estos síntomas, hay muchos otros que se presentan baxo de diferentes aspectos y complicaciones, tanto en sus principios y estados, quanto en las declinaciones y terminaciones (p. 18)

A este respecto, quizá lo más interesante de la Instrucción analizada sea la aparición del vocablo terminación, dado que parece representar un uso novedoso del Ochocientos para denominar la última de las fases mencionadas, si bien tal novedad no oculta que, tal como se observa en los ejemplos presentados, en el siglo de las Independencias se continúa usando de manera general la nomenclatura de la centuria pasada (Ramírez Luengo 2014; Cortés Riveroll 2008).

Pasando ya a los tipos de viruela, como era de esperar se trata de una de las temáticas léxicamente más ricas que aparecen en la Instrucción. Como bien indica Cortés Riveroll (2008: 20), la enfermedad se divide en dos grandes tipos, que denomina variola minor y variola major respectivamente y que se distinguen por el grado de mortandad, mucho más elevado en esta última; esta oposición se hace presente también en la obra de Calleja, quien utiliza las denominaciones de viruelas simples, benignas y regulares en el caso de la primera y viruelas complicadas y malignas en el de las segundas, en línea con las denominaciones presentes ya en la Nueva España y en la metrópoli durante el siglo XVIII (Ramírez Luengo 2014) .

8. Dividense las viruelas en discretas y confluentes; se diferencian aquellas de estas en que las primeras se presentan con pocos granos y pustulas (y son las que llama el pueblo locas) y porque cesa la calentura quando se completa la erupcion; y en las segundas los granos son en grande número, y van acompañados de calenturas altas que no cesar con la facilidad que en las primeras; tanto de las unas como de las otras las hay simples, benignas y regulares; y complicadas y malignas las que se conocen con los nombres de disentéricas, cristalinas, verrugosas, algarrobosas, miliares (p. 17)

Ahora bien, el ejemplo que se acaba de presentar demuestra que quizá uno de los aspectos más relevantes del texto estudiado sea que, junto a esta primera clasificación, se presentan otras dos que parten de principios diferentes: por un lado, se emplea como criterio la cantidad de pústulas que aparecen, lo que permite al texto hablar de viruelas discretas y confluentes, frente a lo que ocurre en otras obras del siglo pasado (Pereyra 1768), caracterizadas por la escasez o por su "gran

6 De igual forma, se observa en el texto el uso del término viruelas (locas) como voz popular para referirse a la varicela, en sintonía con lo que registran Cortés Riveroll (2008: 20) y Ramírez Luengo (2014: 189) para el siglo XVIII y se mantiene popularmente hasta el día de hoy. 
número" de ellas (Calleja 1814: 17) respectivamente; por otro lado, también la forma que adopta la pústula sirve como criterio clasificatorio, y en este caso se facilitan denominaciones como disentéricas, cristalinas, verrugosas, algarrobosas o miliares, algunas de las cuales se descubren ya en la Nueva España del siglo XVIII (Ramírez Luengo 2014: 195), si bien otras -como verrugosas, algarrobosas o miliares- parecen ser innovaciones propias del ochocientos y presentar un uso generalizado a ambos lados del Atlántico, a la luz de este texto y de los datos, por ejemplo, del diccionario de Ballano (1817: 210-218).

Finalmente, el mismo título de la Instrucción demuestra que uno de los objetivos más notorios del texto es dar a conocer la vacuna, justificar su empleo y preparar a los médicos de la Nueva España para su utilización; a este respecto, si bien la vacuna es descubierta en 1796 por Edward Jenner en Inglaterra (Stern y Markel 2005: 612), no es hasta el siglo siguiente que este proceso llega al ámbito hispánico, muy especialmente por medio de la Real Expedición Filantrópica de la Vacuna, que tiene lugar entre los años 1803 y 1806 y con la que Carlos IV distribuye dicho descubrimiento por las colonias del Imperio español (Perigüell y Añón 2003). Por supuesto, estos procesos se ven bien representado léxicamente dentro del documento con el empleo de términos como vacuna y sus derivados vacunación, vacunar y vacunada/o, que se repiten en el texto con un total de 65 apariciones, lo que demuestra no sólo la vitalidad del vocablo en el español novohispano de los primeros años del siglo XIX, sino también "la rápida difusión de términos relativamente novedosos [...] entre los galenos del actual México, en línea con la rapidísima difusión de tal procedimiento preventivo por estas tierras" (Gómez de Enterría et al. 2016: 89) ${ }^{7}$ (ejemplos 9-12):

9. Por tanto, para aquellas poblaciones que pueda remitirse les la vacuna, se acompañan las breves instrucciones impresas, y con presencia de ellas qualquiera (sea quien se fuese) podrá vacunar y observar sus progresos sin cometer error (p. 23)

10. En algunos es necesario repetir la vacunacion muchas veces, hasta que se presente el grano vacuno, pues de lo contrario no quedan libres de las viruelas. (p. 8)

11. Quando la ha habido, con solo picar y desahogar el grano con la punta de la aguja para vacunar, ó con qualesquiera otra, cede: ó bien se le moja un pedacito de lienzo en leche, y se pone sobre la areola. (pp. 6-7)

12. El Sr. Dr. D. Luis Montaña, [...], inoculó á otros seis niños vacunados: lo mismo hizo despues otros once (p. 12)

Junto a la vacunación, el texto demuestra la persistencia del antiguo método de tratamiento, la inoculación, que también aparece en sus páginas y presenta algunos derivados como inocular e inoculados, tal como se puede observar en los siguientes ejemplos:

13. Si en la epidemia inmediata pasada de viruelas del año de 1797 se socorrieron por la Junta principal de Caridad de esta Capital [...], debe atribuirse el buen éxito de la de 1797 [...] á la inoculacion de la viruela, que aunque no adaptada generalmente por capricho y timidez (p. 14)

7 Téngase en cuenta, a este respecto, que de acuerdo con CORDE (consultado 21/08/2020) los primeros ejemplos de vacuna con su significación médica se registran en España en 1802 y en América, en concreto Colombia, en 1803, es decir, apenas una década antes de la fecha que se publica el texto que se está analizando. 
14. Mas si por las circunstancias enunciadas no se pudiese obtener en algunos pueblos este don particular de la providencia divina, para libertarlos de las viruelas será conducente no omitan á lo menos inocular con ellas (p. 23)

15. La Junta ha cuidado de visitar á los inoculados, y ha visto por sus propios ojos que no les ha prendido las viruelas naturales en los diez dias que van corridos desde el de la operacion, ni les prenderán ya, pues la inoculacion produce su efecto al quarto ó quinto (p. 12)

En relación con ambos conceptos, vacunación e inoculación, vale la pena resaltar que, en contraste con la sinonimia que parecen mostrar hoy en día (DLE 2019: s.v. inocular, vacunar) ${ }^{8}$, dentro del corpus sus significados primeros se encuentran bien diferenciados, el primero categorizado como un método preservativo o prophyláctico mientras que el segundo se entiende como uno paliativo o de tratamiento, es decir, la vacuna se utiliza para prevenir el posible contagio mientras que la inoculación es empleada cuando este ya se ha producido, tal y como se ve en el siguiente ejemplo':

16. Hay una gran diferencia entre la curacion preservativa ó prophyláctica, y la paliativa: [...] la vacuna es la preservativa o prophylactica, la que en lo absoluto no causa el mas minimo perjuicio y liberta de las viruelas; y la inoculacion de las viruelas es la paliativa, la que aun quando no carece de peligro, pero con relacion a la voracidad de acometer las viruelas, es preferible: de consiguiente esta bien claro, que pudiendo impedirse la enfermedad con la preservativa ó prophylactica, debe ser esta preferida. (p. 15)

\section{Unas primeras conclusiones}

Así pues, a partir del análisis desarrollado hasta el momento, es posible señalar ya una serie de conclusiones acerca del léxico que se emplea en México de los primeros años del siglo XIX para referirse a la viruela cuya consideración arroja luz sobre la configuración histórica del vocabulario médico en este país.

Respondiendo a uno de los objetivos del estudio, es importante señalar en primer lugar que se identifica la existencia de una clara continuidad entre el léxico de esta obra y el de los textos dieciochescos analizados por Ramírez Luengo (2014), cuestión que se refleja por ejemplo en el uso preferido del plural viruelas sobre el singular para referirse a la dolencia o el empleo de unidades léxicas comunes para denominar las fases que atraviesan los pacientes a lo largo de la enfermedad, con casos como principios y declinaciones, así como para clasificar los distintos tipos de viruela, entre las que se pueden citar viruelas confluentes, discretas, benignas, regulares y malignas. En realidad, no sorprende que esto sea así, dado que la temprana publicación del texto en las primeras décadas del siglo XIX obliga a pensar en una formación dieciochesca de su autor, además de la

8 En concreto, en las acepciones médicas de ambos términos, la tercera de vacunar (DLE, 2019: s.v. vacunar) y la primera de inocular (DLE, 2019: s.v. inocular).

9 A este respecto, es importante que en trabajos futuros se retome esta cuestión y se analice cuándo ocurre el cambio semántico que produce la igualación de ambos conceptos, así como las características de dicho proceso y sus posibles diferencias diatópicas, en España y América. 
reconocida continuidad histórica y cultural que existe entre la centuria ilustrada y las dos primeras décadas del ochocientos (Gómez de Enterría 2014: 202).

No obstante, aun cuando esta continuidad parece ser la norma, lo cierto es que se observan también novedades tales como un aumento en la preferencia de uso del singular viruela sobre su forma plural para referirse a esta enfermedad o incorporaciones de voces que quizá se puedan considerar neologismos del siglo XIX, entre ellos nuevas denominaciones como terminaciones para hacer referencia a una fase de la enfermedad o algunos compuestos sintagmáticos del estilo de viruelas miliares, verrugosas y algarrobosas que se incorporan a la clasificación de los diversos tipos de esta y que están presente en textos de estos mismos momentos como, entre otros, el diccionario de Ballano (1817: 210-218), Bancés (1802) o Colombier (1804).

Finalmente, es importante recordar la falta de interés que los investigadores sobre el vocabulario histórico médico han mostrado por una región como México y de igual forma por el siglo de las Independencias, y por tanto incidir en la necesidad de desarrollar futuros trabajos que agreguen nuevos datos para poder esclarecer la situación que presenta este léxico especializado en el momento señalado.

\section{Referencias bibliográficas}

Ballano, A. (1817). Diccionario de medicina y cirugía o Biblioteca manual médico-quirúrgica (Vol. 5). Madrid: Francisco Martínez Dávila.

Bances, D. (1802). Tratado de la vaccina o viruela vacuna. Pamplona: Imp. Viuda Longas e Hijo.

Calleja, F. M. (1814). Instrucción formada para ministrar la vacuna. México: Oficina de D. Mariano Ontiveros.

Colombier, D. (1804). Biblioteca universal de medicina y cirugía prácticas, medicina militar ó tratado de las enfermedades así internas como externas a que los militares están expuestos en sus diferentes situaciones de paz y guerra (vol. 2). Madrid: Don Mateo Repullés.

[CORDE]: Real Academia Española (2019). Banco de datos CORDE. Corpus diacrónico del español. <http:// www.rae.es>

Cortés Riveroll, J. G. R. (2008). Inicio de la vacunación en la ciudad de Puebla, 1804-1814. Xalapa: Universidad Veracruzana.

[CREA]: Real Academia Española (2019). Corpus de referencia del español actual. <http://www.rae.es/recursos/banco-de-datos/crea>

[DAMER]: Real Academia Española/Asociación de Academias de la Lengua Española (2010): Diccionario de Americanismos. Madrid: Santillana.

[DLE]: Real Academia Española (2014). Diccionario de la Lengua Española. Madrid: Espasa-Calpe.

Franco-Paredes, C.; Lammoglia, L.; \& Santos-Preciado, J. I. (2004). Perspectiva histórica de la viruela en México: Aparición, eliminación y riesgo de reaparición por bioterrorismo. Gaceta médica de México, 140, 3, 321-328.

Gómez de Enterría, J. (2014). El vocabulario de las fiebres epidémicas en el español del siglo XVIII. España y México. In J. L. Ramírez Luengo \& E. P. Velásquez Upegui (Eds.), La historia del español hoy. Estudios y perspectivas (pp. 199-216). Lugo: Axac. 
. (2015). El vocabulario de la medicina en el español del siglo XVIII. In J. M. Martín García (Ed.), Actas del IX Congreso Internacional de Historia de la Lengua Española (vol. 1) (pp. 361-392). Madrid/ Frankfurt: Iberoamericana/Vervuert.

. (2016). Constelación léxica en torno al vocabulario de los fluidos en la medicina del siglo XVIII. In A. López, A. Narbona, \& S. del Rey Quesada (Eds.), El español a través del tiempo: estudios ofrecidos a Rafael Cano Aguilar (pp. 259-275). Sevilla: Universidad de Sevilla.

Gómez de Enterría, J. Ramírez Luengo, J. L. Carpi, E., Delle Pezze, F. Navarro, C. \& Gallardo, N. (2016). Tres momentos fundamentales en la historia de las ideas para la formación del vocabulario científico en el siglo XVIII. In C. Garriga Escribano (Ed.), Lengua de la ciencia e historiografía (pp. 83-98) A Coruña: Universidade da Coruña.

Gutiérrez Rodilla, B. M. (1993). Los términos relacionados con la medicina en el Diccionario de Autoridades. Boletín de la Real Academia Española, 73, 260, 463-512.

. (2014). El lenguaje de la medicina en español: Cómo hemos llegado hasta aquí y qué futuro nos espera.Panace@: Revista de Medicina, Lenguajey Traducción, 15, 86-94.

Pereyra. L. J. (1768). Tratado completo de calenturas fundado sobre las leyese de la inflamación y la putrefacción. Madrid: Imprenta de Antonio Marin.

Perigüell, E. B.; \& Añón, R. B. (2003). En el nombre de los niños: La Real Expedición Filantrópica de la Vacuna (1803-1806). Madrid: Asociación Española de Pediatría.

Ramírez Luengo, J. L. (2014). Un aporte a la historia del léxico médico en América: El vocabulario de la viruela en la Nueva España dieciochesca. Anuario de Letras: Lingüística y filología, 2, 1, 179-216.

. (2015). Aproximación al léxico de la medicina en el Buenos Aires del siglo XVIII. In J. M. García Martín (Ed.), Actas del IX Congreso Internacional de Historia de la Lengua Española (vol. 2) (pp. 21512164). Madrid/Frankfurt: Iberoamericana/Vervuert.

Stern, A. M.; \& Markel, H. (2005). The history of vaccines and immunization: Familiar patterns, new challenges. Health affairs, 24, 611-621. 
